\title{
UV-A light-assisted gas-phase formic acid decomposition on photo-thermo $\mathrm{Ru} / \mathrm{TiO}_{2}$ catalyst
}

\author{
Javier Ivanez ${ }^{1}$, Patricia Garcia-Munoz ${ }^{1}$, Agnieszka M. Ruppert ${ }^{2}$, Nicolas Keller ${ }^{1 *}$
}

(1) Institut de Chimie et Procédés pour l'Energie, l'Environnement et la Santé (ICPEES),

CNRS/University of Strasbourg,25 rue Becquerel 67087 Strasbourg, France.

(2) Institute of General and Ecological Chemistry, Faculty of Chemistry, Lodz University of Technology, ul. Żeromskiego 116, 90-924, Łódź, Poland.

Corresponding authors(*): nkeller@unistra.fr

\begin{abstract}
Although solar energy is considered as one of the ideal abundant sources of renewable energy to be integrated into catalytic processing, photonic and thermal excitations were perceived till recently as independent strategies in overcoming Arrhenius-type activation energy barriers in catalytic reactions. However, this dual-mode excitation of catalysts is receiving a growing interest nowadays due to promising evidence of synergy effects. $\mathrm{A} \mathrm{Ru} / \mathrm{TiO}_{2}$ photo-thermo- catalyst was prepared according to a UV-A light photo-assisted synthesis method allowing a fine control of the $\mathrm{Ru}$ nanoparticle size distribution, and the influence of a combined photonic (UV-A) and thermal activation on its performances in the gas phase decomposition of formic acid into hydrogen was investigated. The results showed that a dual photonic/thermal excitation in a onepot operation allows to increase the formic acid conversion and consequently the production of hydrogen $v s$. the reaction in the dark, the enhancement being all the more pronounced as the irradiance is high. The combined excitation allowed to drive the reaction at lower temperatures
\end{abstract}


upon irradiation while maintaining a similar conversion level. This low-temperature shift was all the more marked as the irradiance was high, and was accompanied by a strong increase in the selectivity to hydrogen. The change in both conversion and selectivity patterns suggested the implication of the light-excited electrons in the non-plasmonic $\mathrm{Ru}$ nanoparticles for conducting the reaction through an alternative low-energy transition state, with a lowering of the apparent energy activation, rather than a mechanism of localized-heat delivery.

Keywords: Light-assisted catalysis ; photothermal ; Apparent activation energy ; Ru nanoparticles ; $\mathrm{TiO}_{2}$; formic acid decomposition

\section{INTRODUCTION}

While thermal and photonic catalysis are still perceived as distinctly independent strategies in overcoming (Arrhenius-type) activation energy barriers in chemical reactions, there is growing evidence that synergy effects exist under dual-mode excitation that offer real prospects for exploitation in the necessary transition from fossil-based resources to a more sustainable energy and chemicals economy, as well as for mitigating the carbon footprint of environmental (cleaning-up) remediation reactions. On one hand, heterogeneous catalysis is playing a pivotal role in the efficient implementation of chemical reactions and in the establishment of a modern chemical industry, although achieving high activity and selectivity remains still highly challenging for many catalytic conversion processes [1,2]. On another hand, solar energy is considered as one of the ideal (abundant) sources of renewable energy for the future to be linked with chemical processing. Its harnessing and integration into catalytic processing is proposed to play a major role in the drive towards more sustainable chemical processes, and in the establishment of a low carbon energy economy $[3,4]$. 
The primary aim of coupling both photonic and thermal excitation in a one-pot operation is in consequence driven by the imperative of improving the chemical process sustainability with lowering of the environmental and energetic footprint. This motivation is concretely materialized by the need of obtaining the same product yields at lower temperature or more globally under milder conditions, of accelerating reaction rates under given reaction conditions for increasing production yields and reducing the processing times, and/or of orientating the reaction selectivities [5-10].

The combined effects of photonic and thermal excitation is consequently an emerging area that arouses a lot of hope in the last decade in applied catalysis, as highlighted by the continuously-broadening and -diversifying span of novel applications in the Energy and Environment fields. Synergies have already been reported in environmental reactions targeting air detoxification and water treatment, notably eg. the mineralization of Volatile Organic Compounds like BTEX, alcohols or aldehydes, the $\mathrm{CO}$ oxidation, or the mineralization of dyes and phenolic refractory compounds [5,11-14]. Also, great advances have been made recently for high-impact reactions in the field of chemical synthesis and energy, like the production of high value-added (specialty) compounds by oxygenates conversion [15], the on-site (refinery) process hydrogen generation by renewable oxygenate(s) reforming [16], the Fischer-Tropsch synthesis towards renewable hydrocarbons [17], the Haber-Bosch ammonia synthesis [18], and the burgeoning research field of the $\mathrm{CO}_{2}$ reduction/hydrogenation whether methanation via the Sabatier reaction [19], reverse water gas shift reaction [20], short-chain alcohol synthesis [21], dry reforming [22], and artificial photo-synthesis for solar fuels are concerned [23].

However, no standardized definition has been established yet, eg. the photothermal terminology being used by the groups of Ozin and Ye for referring to synergies in simultaneous illumination under heating, and to the localized heating effect resulting from light absorption and non-radiative relaxation, respectively $[6,8]$. By contrast, Nair et al. differentiates photo- 
thermo- from thermo-photo- catalysis whether the reaction mechanisms involved are related to a photonic effect applied to a thermal catalyst, or to a thermal influence on a photocatalyst [5], while the review of Tang et al. does not discriminate between both phenomena by using the term photo-thermal catalysis [7]. The primary key-figure of a so-called photo-thermo- catalyst - the generic term we will use henceforth independently of the possible underlying mechanisms to describe dual heat and photonic excitation of the catalyst - is that at least one component must be light-sensitive, regardless of whether this is a semiconductor or not [24-26].

This work aims at studying the influence of the dual photonic (UV-A) and thermal activation of a $\mathrm{Ru} / \mathrm{TiO}_{2}$ catalyst on its performances in the gas phase decomposition of formic acid (FA) into hydrogen, taken here as model reaction. This reaction is also of high interest, as FA is a promising $\mathrm{H}_{2}$ carrier for storage $[27,28]$ and can be used as internal $\mathrm{H}_{2}$ source $\left(\mathrm{H}_{2}\right.$ donor $)$ for performing catalytic transfer hydrogenation reactions [29,30]. This hydrogen donormediated strategy instead of using external pressurized $\mathrm{H}_{2}$ is a step forward in the design of sustainable hydrogenation processes [31,32]. FA decomposition may occur through both dehydrogenation (Eq. 1) and dehydration (Eq. 2) pathways, with the production of $\mathrm{H}_{2}$ and $\mathrm{CO}_{2}$, and of $\mathrm{CO}$ and $\mathrm{H}_{2} \mathrm{O}$, respectively. In some cases, water gas shift reaction can also be observed (Eq. 3), while CO is known to act also as a poison for the catalyst active sites [33].

$$
\begin{aligned}
& \mathrm{HCOOH} \rightarrow \mathrm{H}_{2}+\mathrm{CO}_{2} \\
& \mathrm{HCOOH} \rightarrow \mathrm{CO}+2 \mathrm{H}_{2} \mathrm{O} \\
& \mathrm{CO}+\mathrm{H}_{2} \mathrm{O} \rightarrow \mathrm{H}_{2}+\mathrm{CO}_{2}
\end{aligned}
$$

The $\mathrm{Ru} / \mathrm{TiO}_{2}$ catalyst was indeed recently reported as a very promising system capable of meeting the challenge of catalyzing both the dehydrogenation of FA to $\mathrm{H}_{2}$ and the hydrogenation of levulinic acid biomass-derived platform molecule into the high value-added $\gamma$-valerolactone under similar reaction [30]. 


\section{EXPERIMENTAL PART}

\subsection{Preparation of the $\mathrm{Ru} / \mathrm{TiO}_{2}$ catalyst by UV-A light photo-assisted synthesis}

Aeroxide ${ }^{\circledR} \mathrm{TiO}_{2}$ P25 was purchased from Evonik ${ }^{\circledR}$ (Evonik Resource Efficiency $\mathrm{GmbH}$, Hanau-Wolfgang, Germany). The supported photo-thermo- catalyst was prepared according to a UV-A light photo-assisted synthesis method allowing a fine control of the Ru nanoparticle size distribution [30]. Ruthenium (III) chloride hydrate $\left(\mathrm{RuCl}_{3} \bullet \mathrm{xH}_{2} \mathrm{O}, 40 \% \mathrm{Ru}\right.$ min. content, Sigma-Aldrich) was used as ruthenium precursor, and dissolved under stirring in $10 \mathrm{~mL}$ of methanol for $12 \mathrm{~h}$, before an aliquot was taken to prepare a $100 \mathrm{ml} 10 \% \mathrm{v} / \mathrm{v}$ methanol aqueous solution in a beaker-type glass reactor with the desired concentration of the metallic precursor (natural $\mathrm{pH}$ value of 4.3). $\mathrm{TiO}_{2}$ at a concentration of $1 \mathrm{~g} / \mathrm{L}$ was further dispersed under stirring in $100 \mathrm{~mL}$ of the ruthenium precursor solution in a beaker-type glass reactor. Prior to irradiation, the suspension was maintained under stirring for $1 \mathrm{~h}$ to ensure the establishment of the dark adsorption-desorption equilibrium, before to be exposed under stirring to UV-A light at $69.6 \mathrm{~W} \mathrm{~m}^{-2}(\lambda=365 \mathrm{~nm}$, Philips $24 \mathrm{~W} / 10 / 4 \mathrm{P}$ lamps $)$. At each time interval, $1 \mathrm{~mL}$ of solution was sampled and filtrated through a $0.20 \mathrm{~mm}$ porosity filter (Aireka Cells) to remove the titania powder if any. The synthesis was followed by UV/Vis spectrophotometry using a UV-1600 PC spectrophotometer (VWR) by monitoring the disappearance of the main absorption peak at $\lambda=324 \mathrm{~nm}$ for the ruthenium precursor. After completion of the process, the suspended catalyst was recovered by vacuum filtration and dried at $100^{\circ} \mathrm{C}$ for $1 \mathrm{~h}$.

\subsection{Characterisation techniques}

The ruthenium loadings were determined by chemical analysis through inductively coupled plasma optical emission spectroscopy (ICP-OES) carried out on an Optima 7000 DV 
spectrometer (Perkin Elmer), after a microwave-assisted acidic dissolution in aqua regia at $185^{\circ} \mathrm{C}$ under autogenic pressure.

Transmission electron microscopy (TEM) was carried in secondary electron mode on a JEOL $2100 \mathrm{~F}$ microscope with a point resolution of $0.2 \mathrm{~nm}$. Each powdery sample was sonicated in ethanol before a drop of the suspension was deposited onto a copper grid covered by a holey carbon membrane for observation. The interplanar spacings were calculated using Image J software, as well as the Ru nanoparticle size distribution, obtained by averaging 300 particles from the TEM images

X-Ray Photoelectron Spectroscopy (XPS) characterization was performed on a ThermoVG Multilab ESCA 3000 spectrometer (Al K $\alpha$ anode at $h \lambda=1486.6 \mathrm{eV}$ ). The energy shift due to electrostatic charging was adjusted using the adventious sp2 carbon $\mathrm{C} 1 \mathrm{~s}$ band at $284.5 \mathrm{eV}$. Contributions with Doniach-Sunjic shape and a S-shaped Shirley type background were used, while the surface atomic ratios and the surface atomic concentrations were obtained using the appropriate experimental sensitivity factors, as determined by Scofield.

Time-of-Flight Secondary Ion Mass Spectrometry (ToF-SIMS) analysis was performed using an ION-TOF instrument (TOF-SIMS IV) equipped with a $25 \mathrm{kV}$ pulsed $\mathrm{Bi}_{3}{ }^{+}$primary ion gun in the static mode. A pulsed low-energy electron flood gun was used for charge neutralization. The analyzed sample area was $500 \mu \mathrm{m}$ x $500 \mu \mathrm{m}$.

Measurements of light irradiances for the photo-assisted synthesis and the catalytic tests were performed using a wideband RPS900-W rapid portable spectroradiometer from International Light Technology.

\subsection{Catalytic tests}

The photo-thermo FA decomposition catalytic tests were carried with a FA concentration of $4600 \mathrm{ppm}_{\mathrm{v}}$ and using Ar as carrier gas at $14.7 \mathrm{~mL} / \mathrm{min}$. The FA-containing inlet flow was 
obtained by diluting a concentrated FA/Ar flow with a pure Ar carrier flow. To this end, an Ar flow (Air Liquide, ALPHAGAZ ${ }^{\mathrm{TM}} 1, \geq 99,999 \%$ ) was bubbled in a temperature-controlled saturator containing liquid phase formic acid $(\mathrm{HCOOH}$, Sigma Aldrich, $>95 \%)$ at $15^{\circ} \mathrm{C}$ and atmospheric pressure. Thus, the concentration of gas phase $\mathrm{HCOOH}$ was related to the vapour pressure of $\mathrm{HCOOH}$ at working temperature and pressure conditions. This concentrated $\mathrm{FA} / \mathrm{Ar}$ flow was further mixed with an additional Ar flow to obtain the required FA concentration at the working flow rate, corresponding to a Weight hourly space velocity (WHSV) of $4.24 \mathrm{~h}^{-1}$. In-Flow Bronkhorst flow meter (Bronkhorst ${ }^{\circledR}$ High-Tech, the Netherlands) allowed the control of the FA-containing air flow, while the main Ar carrier flow was controlled via a Brooks 5850 massflow meter.

The continuous-flow photo-thermo reactor consisted in a Harrick Scientific HVC-MRA 5 reaction chamber made from SS-316 alloy. $1.8 \mathrm{mg}$ of the catalyst was homogeneously deposited as a thin layer at the surface density of $6 \mathrm{mg} / \mathrm{cm}^{2}$ on a stainless meshed grid allowing the catalyst and the reactor to operate in a flow-through mode. The catalyst was homogeneously heated using an external cartridge heater monitored by a K-type thermocouple $\left( \pm 1^{\circ} \mathrm{C}\right)$, and using a high flow rate water cooling system for maintaining a constant (bulk) temperature. The catalyst was irradiated via a quartz window using a Thorlab M365LP1 LED ( $\lambda=365 \mathrm{~nm})$ with tunable and calibrated irradiance within the $0-365 \mathrm{~mW} / \mathrm{cm}^{2}$ range. Prior to any experiment, oxygen was removed by argon flushing. The photo-/thermo- catalytic behavior was obtained by on-line quantification of the outlet flow using a R3000A gas micro-chromatography (SRA instruments), equipped with micro-TCDs, and allowing the quantification of $\mathrm{HCOOH}, \mathrm{H}_{2}, \mathrm{O}_{2}$, $\mathrm{CO}, \mathrm{CO}_{2}$ and organics on 5A molecular sieve, OV1, PoraPlotQ and Stabilwax columns.

The activity of the catalyst was expressed in terms of FA conversion, $\mathrm{H}_{2}$ selectivity, as well as of $\mathrm{H}_{2}, \mathrm{CO}_{2}$ and $\mathrm{CO}$ production in mmol.g $\mathrm{g}^{-1} \cdot \mathrm{h}^{-1}$, calculated as follows (Eqs. 5-6) : 


$$
\begin{aligned}
& \text { FA conversion }(\%)=\frac{\left[\mathrm{H}_{2}\right]+[\mathrm{CO}]}{\left[\mathrm{FA}_{i n}\right]} \times 100 \\
& \mathrm{H}_{2} \text { selectivity }(\%)=\frac{\left[\mathrm{H}_{2}\right]}{[\mathrm{CO}]+\left[\mathrm{H}_{2}\right]} \times 100
\end{aligned}
$$

The carbon balance was verified as follows :

$$
\text { C balance }(\%)=\frac{\left[\mathrm{CO}_{2}\right]+[\mathrm{CO}]+\left[\mathrm{FA}_{\text {out }}\right]}{\left[\mathrm{FA}_{\text {in }}\right]} \times 100
$$

$\left[\mathrm{FA}_{\text {in }}\right]$ and $\left[\mathrm{FA}_{\text {out }}\right]$ are the inlet and outlet FA concentrations, respectively. It must be said that whatever the reaction conditions (temperature and light irradiance), $\mathrm{H}_{2}$ and $\mathrm{CO}_{2}$ were formed with the equimolar ratio associated to the dehydrogenation path (as evidenced in the corresponding figures), so that $\mathrm{H}_{2}$ or $\mathrm{CO}_{2}$ can be independently chosen for calculating both $\mathrm{FA}$ conversion and $\mathrm{H}_{2}$ selectivity. The carbon balance was calculated within the $98-102 \%$ range for all catalytic tests.

\section{RESULTS AND DISCUSSION}

3.1 Synthesis monitoring and characterization of the $\mathrm{Ru} / \mathrm{TiO}_{2}$ catalyst

The UV-Vis spectrophotometry monitoring of the photo-assisted synthesis of the $\mathrm{Ru} / \mathrm{TiO}{ }_{2}$ catalyst at $0.5 \mathrm{wt} . \%$ is depicted in Fig. S1 with the evolution of the relative concentration of the $\mathrm{Ru}$ precursor and of the corresponding UV-vis absorbance spectra upon solar light illumination. First, no photolysis of the precursor occurred under solar light in the absence of $\mathrm{TiO}_{2}$. By contrast, complete disappearance of the Ru precursor was observed upon illumination of the $\mathrm{TiO}_{2}$ support suspension for a reaction time of $5 \mathrm{~h} \mathrm{~min}$. The ruthenium content in the catalyst determined by ICP-OES was 0.46 wt. $\%$, in good agreement with the nominal targeted value of 
$0.5 \mathrm{wt} \%$. TEM images revealed the synthesis of $\mathrm{Ru}$ nanoparticles at the $\mathrm{TiO}_{2}$ support surface, with a sub-nanometric and narrow particle size distribution centred on $0.6 \mathrm{~nm}$ and with a Full Width at Half Maximum (FWHM) of $0.16 \mathrm{~nm}$ (Fig. 1A-C). The resulting catalyst was characterized by a very high and homogeneous nanoparticle dispersion, with no formation of aggregates. The metallic nature of the Ru nanoparticles was confirmed by high resolution TEM analysis, that evidences the $2.1 \AA$ interplane distance characteristic of the (101) planes of metallic $\mathrm{Ru}$ [34], as well as by XPS surface characterization. Indeed, the $\mathrm{Ru} 3 \mathrm{~d}$ core orbital XPS spectra shown in Fig. 1D exhibits two doublet contributions at $280.4 \mathrm{eV}$ and $282.0 \mathrm{eV}$ with a $4.1 \mathrm{eV}$ spin orbit splitting constant, that can be assigned to both metallic $\mathrm{Ru}^{0}$ and $\mathrm{Ru}^{\delta+}$ species, respectively, in addition to the multi-contribution envelope resulting from the presence of adventious carbon and overlapping with the $\mathrm{Ru} 3 \mathrm{~d}$ region $[33,35,36]$. Considering the $\mathrm{Ru}^{0} / \mathrm{Ru}^{\delta+}$ surface concentration ratio calculated at $79 / 21 \pm 6$ and the small average size of the nanoparticles, the presence of oxidized $\mathrm{Ru}^{\delta+}$ species was proposed to result from the natural surface oxidation of the metallic $\mathrm{Ru}$ species when exposed to the air, as reported for many supported noble metals. However, the presence of $\mathrm{Ru}^{\delta+}$ species might also find its origin in the formation of Ti-O-Ru interfacial bonds upon the illumination and the associated reaction between the $\mathrm{Ru}$ complexes and the photogenerated electron. Further, the very high $\mathrm{Ru} / \mathrm{Ti}$ surface atomic ratio of 0.12 when considering the low $\mathrm{Ru}$ content of 0.5 wt.\%, was characteristic of both the very dispersion and the very small size of the nanoparticles. In addition, it is worth to note that, the presence of residual chlorine species at the surface was evidenced by ToF-SIMS analysis, unlike what was observed by the XPS surface analysis $(\mathrm{Cl}$ $2 p$ spectra not shown). This discrepancy probably finds its origin in the far smaller analysis thickness in ToF-SIMS when compared to that of XPS. Analysis of selected ions suggested that the residual top-surface $\mathrm{Cl}$ species are in interaction with the $\mathrm{TiO}_{2}$ support rather than with the 
$\mathrm{Ru}$ nanoparticles, as evidenced by the detection of the characteristic $\mathrm{TiO}_{2} \mathrm{Cl}^{-}$ion and the absence of any characteristic $\mathrm{Ru}_{\mathrm{x}} \mathrm{Cl}_{\mathrm{y}}{ }^{-}$and $\mathrm{RuO}_{2} \mathrm{Cl}_{\mathrm{y}}{ }^{-}$ions.

\subsection{Catalytic activity}

\subsubsection{Activity of bare $\mathrm{TiO}_{2}$}

Figure 2 depicts the influence of both the reaction temperature in the $130-190^{\circ} \mathrm{C}$ range and the UV-A irradiance $\left(0-365 \mathrm{~mW} / \mathrm{cm}^{2}\right)$ on the catalytic activity of the pure $\mathrm{TiO}_{2}-\mathrm{P} 25$ support in the gas phase formic acid decomposition. The results obtained revealed that FA decomposition only occurred through the dehydration pathway, $\mathrm{CO}$ being the only reaction product detected, neither $\mathrm{H}_{2}$ nor $\mathrm{CO}_{2}$ being formed, independently of the reaction temperature and whether the reaction is performed in the dark or under irradiation. Higher the reaction temperature, higher the FA conversion, with a conversion increase from $3 \%$ to $33 \%$ accompanied by an increase in the $\mathrm{CO}$ formation from 2 to $22 \mathrm{mmol} / \mathrm{g} / \mathrm{h}$ when the reaction temperature was increased from $130^{\circ} \mathrm{C}$ to $190^{\circ} \mathrm{C}$ in the dark. Performing the reaction under irradiation enhanced the conversion and corresponding the $\mathrm{CO}$ formation, all the more pronounced as the irradiance is high, and the FA conversion reached $85 \%$ with a CO formation of $57 \mathrm{mmol} / \mathrm{g} / \mathrm{h}$ at a temperature of $190^{\circ} \mathrm{C}$ with an irradiance of $365 \mathrm{~mW} / \mathrm{cm}^{2}$.

FA decomposition is known to take place on transition metal oxides surfaces, with first the donation of a proton to the catalyst to form the adsorbed formate intermediate. [37] The reaction on $\mathrm{TiO}_{2}$ has been reported to be selective towards $\mathrm{CO}$ formation (FA dehydration) [38,39], and Henderson proposed a mechanism involving a complex set of chemical reactions, with the formation of water and the creation of oxygen vacancies by the reaction of the acid proton with the oxide lattice (Eqs. 8,9), and subsequently the decomposition of the adsorbed formate with the release of CO (Eqs. 10-12) [40]. 


$$
\begin{aligned}
& 2 \mathrm{HCOOH}+2 \mathrm{O}^{2-}{ }_{\text {lattice }} \rightarrow 2 \mathrm{HCOO}^{-}{ }_{\mathrm{ad}}+2 \mathrm{OH}^{-}{ }_{\text {lattice }} \\
& 2 \mathrm{OH}^{-}{ }_{\text {lattice }} \rightarrow \mathrm{H} \mathrm{O}+\mathrm{O}^{2-}{ }_{\text {lattice }}+\mathrm{vac} \\
& 2 \mathrm{HCOO}^{-}{ }_{\text {ad }} \rightarrow 2 \mathrm{CO}+2 \mathrm{OH}^{-}{ }_{\text {ad }} \\
& 2 \mathrm{OH}^{-}{ }_{\text {ad }} \rightarrow \mathrm{H}_{2} \mathrm{O}+\mathrm{O}^{2-}{ }_{\text {ad }} \\
& \mathrm{O}^{2-}{ }_{\text {ad }}+\text { vac } \rightarrow \mathrm{O}^{2-}{ }_{\text {lattice }}
\end{aligned}
$$

\subsubsection{Activity of the photo-thermo $\mathrm{Ru} / \mathrm{TiO}_{2}$ catalyst}

Figure 3 depicts the influence of both the reaction temperature and the UV-A irradiance $\left(0-365 \mathrm{~mW} / \mathrm{cm}^{2}\right)$ on the performances of the $\mathrm{Ru} / \mathrm{TiO}_{2}$ catalyst in the gas phase $\mathrm{FA}$ decomposition, while the influence of the UV-A light irradiance is directly visualized in Figure S2. In the dark, increasing the temperature from $25^{\circ} \mathrm{C}$ to $210^{\circ} \mathrm{C}$ led to an increase in the FA conversion in pure thermal catalysis from a non-measurable value to $64 \%$. Independently of the reaction temperature, performing the reaction under irradiation increased strongly the FA conversion. The enhancement being all the more marked as the irradiance is high, with eg. at $130^{\circ} \mathrm{C}$ a conversion reaching $70 \%$ at $365 \mathrm{~mW} / \mathrm{cm}^{2}$ while a low conversion of $1.6 \%$ was observed in the dark. Even at $25^{\circ} \mathrm{C}$, the gain in conversion upon irradiation was noticeable, with an increase from a non-measurable value in the dark up to $9 \%$ with a $365 \mathrm{~mW} / \mathrm{cm}^{2}$ irradiance.

By contrast to the pure dehydration activity of the $\mathrm{TiO}_{2}$ support, both dehydrogenation and dehydration reactions were observed on the $\mathrm{Ru} / \mathrm{TiO}_{2}$ catalyst independently of the reaction temperature and of the UV-A light irradiance, and the selectivity patterns towards $\mathrm{H}_{2}$ and $\mathrm{CO}_{2}$ is shown in Figure 4.

In the dark, the increase in conversion with the increase in temperature was accompanied by an increase in both $\mathrm{CO}$ and $\mathrm{H}_{2}$ formations, eg. from 1 to $13 \mathrm{mmol} / \mathrm{g} / \mathrm{h}$ and 0.1 to $10 \mathrm{mmol} / \mathrm{g} / \mathrm{h}$, respectively, when the reaction temperature was increased from $130^{\circ} \mathrm{C}$ to $190^{\circ} \mathrm{C}$ and the $\mathrm{FA}$ conversion increased from $1.6 \%$ to $37 \%$, corresponding to an increase in $\mathrm{H}_{2}$ selectivity from 
$9 \%$ to ca. $43 \%$. When the reaction was conducted under irradiation, the enhanced conversion was associated to an increase of both $\mathrm{H}_{2}$ and $\mathrm{CO}$ formations, as well as of the selectivity to $\mathrm{H}_{2}$, all the more pronounced as the irradiance is high. The FA conversion reached $86 \%$ with a $\mathrm{H}_{2}$ and $\mathrm{CO}$ formation of $46.4 \mathrm{mmol} / \mathrm{g} / \mathrm{h}$ and $11.7 \mathrm{mmol} / \mathrm{g} / \mathrm{h}$, respectively, at the temperature of $170^{\circ} \mathrm{C}$ with an irradiance of $365 \mathrm{~mW} / \mathrm{cm}^{2}$, corresponding to a strongly enhanced selectivity to $\mathrm{H}_{2}$ of $80 \%$. Whatever the temperature, the enhancement of the FA conversion was accompanied by a strong increase in the selectivity to $\mathrm{H}_{2}$. It must be said that independently of the irradiance and of the temperature, $\mathrm{H}_{2}$ and $\mathrm{CO}_{2}$ were formed with an equimolar ratio, so that side reactions that would contribute to lower the selectivity to $\mathrm{H}_{2}$ (Eqs. 13-15) were not observed in the reaction condition [33].

$$
\begin{aligned}
& \mathrm{CO}+3 \mathrm{H}_{2} \rightarrow \mathrm{CH}_{4}+\mathrm{H}_{2} \mathrm{O} \\
& \mathrm{CO}_{2}+4 \mathrm{H}_{2} \rightarrow \mathrm{CH}_{4}+2 \mathrm{H}_{2} \mathrm{O} \\
& 2 \mathrm{HCOOH} \rightarrow \mathrm{HCHO}+\mathrm{CO}_{2}+\mathrm{H}_{2} \mathrm{O}
\end{aligned}
$$

Considering that the $\mathrm{TiO}_{2}$ surface is active for the selective dehydration of $\mathrm{FA}$ into $\mathrm{CO}$, we can suggest that the $\mathrm{CO}$ formation also might result from the activity of the $\mathrm{TiO}_{2}$ surfaces noncovered by the $\mathrm{Ru}$ nanoparticles, whether they are in the close vicinity of the metallic nanoparticles or not.

The results demonstrated that coupling both photonic and thermal excitation in a one-pot operation allows to increase the FA conversion and in consequence the $\mathrm{H}_{2}$ production when compared to the reaction in the dark, the enhancement being all the more pronounced as the irradiance is high. In other words, similar FA conversion and $\mathrm{H}_{2}$ production could be achieved at lower operating temperature, ie. under milder reaction conditions, eg. working at $365 \mathrm{~mW} / \mathrm{cm}^{2}$ allowed to lower the temperature from $190^{\circ} \mathrm{C}$ down to $90^{\circ} \mathrm{C}$, while maintaining similar FA 
conversion $\left(37 \%\right.$ in the dark at $190^{\circ} \mathrm{C} v s$. and $40 \%$ at $\left.90^{\circ} \mathrm{C} / 365 \mathrm{~mW} / \mathrm{cm}^{2}\right)$. This lowering of the work temperature was further accompanied by an increase in the selectivity to $\mathrm{H}_{2}$, from $43 \%$ in the dark at $190^{\circ} \mathrm{C}$ to $62 \%$ at $90^{\circ} \mathrm{C} / 365 \mathrm{~mW} / \mathrm{cm}^{2}$ ). A similar behaviour was observed at other temperatures, such as $\mathrm{eg}$. at $170^{\circ} \mathrm{C}$ and $150^{\circ} \mathrm{C}$. Indeed, working at $290 \mathrm{~mW} / \mathrm{cm}^{2}$ allowed to lower the temperature from $170^{\circ} \mathrm{C}$ down to $70^{\circ} \mathrm{C}$, while maintaining similar $\mathrm{FA}$ conversion $\left(12.2 \%\right.$ in the dark at $170^{\circ} \mathrm{C} v s .11 .5 \%$ at $\left.70^{\circ} \mathrm{C} / 290 \mathrm{~mW} / \mathrm{cm}^{2}\right)$, and additionally increasing the selectivity to $\mathrm{H}_{2}$ from $41 \%$ in the dark to $62 \%$ at $70^{\circ} \mathrm{C}$ with light). Also, working at $126 \mathrm{~mW} / \mathrm{cm}^{2}$ allowed to lower the temperature from $150^{\circ} \mathrm{C}$ down to $90^{\circ} \mathrm{C}$, while keeping similar FA conversion $\left(5.1 \%\right.$ in the dark at $150^{\circ} \mathrm{C}$ vs. $4.0 \%$ at $\left.90^{\circ} \mathrm{C} / 126 \mathrm{~mW} / \mathrm{cm}^{2}\right)$, and additionally increasing the selectivity to $\mathrm{H}_{2}$ from $15 \%$ in the dark conditions to $62 \%$ at $90^{\circ} \mathrm{C}$ with light).

In consequence, both the low-temperature shift and the increase in $\mathrm{H}_{2}$ selectivity observed when the $\mathrm{Ru} / \mathrm{TiO}_{2}$ catalyst operates at a lower temperature for achieving a similar FA conversion as that in the dark, can be visualized in Figure 5 as a function of the light irradiance, by extrapolating data from Figure 3. Fig. 5A evidences that the low-temperature shift gained upon illumination is all the more pronounced as the irradiance is high, but also as the reference temperature in the dark is low (within the range of investigated temperatures). What is more, this low-temperature shift was positively accompanied by an important gain in $\mathrm{H}_{2}$ selectivity (Fig. 5B), that is globally all the more marked as the irradiance is high, the strongest increase in $\mathrm{H}_{2}$ selectivity upon illumination being observed $v s$. that recorded at $150 \mathrm{C}^{\circ}$ in the dark. As a result from the simultaneous low-temperature shift while maintaining same FA conversion and increase in $\mathrm{H}_{2}$ selectivity, the gain of catalytic activity upon illumination was in consequence allowing an even more pronounced low-temperature shift to be obtained for reaching the same $\mathrm{H}_{2}$ production level under light than that obtained in the dark at a far higher reaction temperature (Fig. 5C). 


\subsubsection{Discussion}

The light absorption of metal nanoparticles is characterized by a combination between the optical properties of the conduction (free) electrons and those of the bound electrons (localized in filled energy bands lower than the conduction band) [41]. While the absorption of light via localized surface plasmon resonance involves the collective oscillation of conduction electrons, the absorption by the individual bound electrons in their ground state results in interband transitions with the formation of the so-called 'hot' electrons $[42,43]$ in their light-excited energetic state. The respective contributions from both effects depend strongly from the metal, so that although $\mathrm{Ru}$ is not considered as a plasmonic metal and therefore does not exhibit any surface plasmon resonance properties, $\mathrm{Ru}$ nanoparticles have been reported to significantly absorb UV and visible light, through a mechanism implying the interband transition of bound electrons [44-47].

In the wake of the use of localized surface plasmon resonance of plasmonic metal (eg. Au, $\mathrm{Ag}, \mathrm{Cu}$ ) nanoparticles, the light-excited electrons in non-plasmonic nanoparticles have also been proposed to facilitate the chemical transformations of reactants adsorbed at the nanoparticle surface $[41,48,49]$.

In this case, the combined (dual) excitation is taking advantage of the photonic excitation for allowing the reaction to be conducted through an alternative low-energy transition state, and subsequently the thermal excitation to operate on a new dark-type rate-determining-step. This is materialized in a lowering of the apparent energy activation. Hence, the apparent activation energies for both dehydrogenation and dehydration reactions in the dark and under light irradiation were obtained by fitting the reaction data within the $70-210^{\circ} \mathrm{C}$ temperature range to the Arrhenius equation (Figures $6 \mathrm{~A}$ and $6 \mathrm{~B}$ ). The results summarized in Figure $5 \mathrm{C}$ that the apparent activation energy for the dehydrogenation reaction decreased from $106.2 \mathrm{~kJ} / \mathrm{mol}$ in the dark down to $18.0 \mathrm{~kJ} / \mathrm{mol}$ at the highest irradiation of $365 \mathrm{~mW} / \mathrm{cm}^{2}$, while the same trend was 
observed for the dehydration reaction, for which the apparent activation energy was reduced from $64.1 \mathrm{~kJ} / \mathrm{mol}$ in the dark down to $17.3 \mathrm{~kJ} / \mathrm{mol}$ at $365 \mathrm{~mW} / \mathrm{cm}^{2}$. While the apparent activation energy for dehydrogenation overcomes strongly that for dehydration in the dark, the increase in the light irradiance strongly reduced this gap, so that the selectivity to $\mathrm{H}_{2}$ significantly enhanced, with values in the $8-40 \%$ range in the dark yielding the $60-80 \%$ range depending on the reaction temperature.

Another possible mechanism would rely on the use of the photonic excitation as delivery mechanism of localized heat (through non-radiative relaxation). In that case, no change in apparent activation energy is expected, and the reaction would process under combined excitation through a similar mechanism than that operating in the dark, but not at the bulk temperature. However, Figure 5 indicates that applying combined photonic and thermal excitations to the $\mathrm{Ru} / \mathrm{TiO}_{2}$ catalyst not only allowed the catalyst to operate at a lower temperature to achieve a similar FA conversion than that obtained in the dark at a higher temperature, but in addition strongly increased the selectivity to $\mathrm{H}_{2}$. Clear discrimination and quantification between thermal and hot-carrier (non-thermal) effects remains a highly challenging open question under debate [50-54]. However, while we cannot rule out the implication to some extent of a localized heat-delivery mechanism for which the selectivity should not be strongly impacted, the findings suggested that the FA decomposition occurred under dual excitation through a different reaction mechanism, i.e. involving directly the lightexcited electrons (hot-carriers) from the supported $\mathrm{Ru}$ nanoparticles, with in consequence an influence on both conversion and selectivity patterns.

Further, additional studies are ongoing for elucidating the potential implication in the reaction mechanism of the photogenerated charge carriers of the underlying $\mathrm{TiO}_{2}$ support and their consequent role in the change in both conversion and selectivity patterns. 


\section{Conclusion}

$\mathrm{A} \mathrm{TiO}_{2}$ supported $\mathrm{Ru}$ photo-thermo- catalyst was prepared with a $0.5 \mathrm{wt} . \%$ content of $\mathrm{Ru}$ according to a UV-A light photo-assisted synthesis method allowing a fine control of the $\mathrm{Ru}$ nanoparticle size distribution in the sub-nanometric range. Applying a dual (combined) photonic (UV-A) and thermal excitation to the $\mathrm{Ru} / \mathrm{TiO}_{2}$ catalyst strongly boosted the gas phase decomposition of FA into $\mathrm{H}_{2}$, the enhancement of both FA conversion and $\mathrm{H}_{2}$ production being all the more pronounced as the irradiance was high in comparison to the catalyst behaviour in the dark. The dual excitation allowed further to drive the reaction under milder conditions while maintaining similar conversion or $\mathrm{H}_{2}$ production levels, namely at a lower temperature, the lowtemperature shift being in consequence all the more pronounced as the irradiance was high within the $0-365 \mathrm{~mW} / \mathrm{cm}^{2}$ range. When operating at a lower temperature, the irradiated catalyst led in addition to a strong increase in the $\mathrm{H}_{2}$ selectivity, with eg. a lowering of the temperature from $190^{\circ} \mathrm{C}$ to $90^{\circ} \mathrm{C}$ under $365 \mathrm{~mW} / \mathrm{cm}^{2}$ irradiance illumination while maintaining a similar FA conversion of $c a .40 \%$ together with a gain in $\mathrm{H}_{2}$ selectivity from $43 \%$ in the dark at $190^{\circ} \mathrm{C}$ up to $62 \%$ under light at $90^{\circ} \mathrm{C}$. The change in both conversion and selectivity patterns upon combined excitation suggested the implication of the light-excited (hot-carrier) electrons in the non-plasmonic $\mathrm{Ru}$ nanoparticles for conducting the reaction through an alternative low-energy transition state, with a lowering of the apparent energy activation, rather than the implementation of a localized heat-delivery mechanism.

Forthcoming studies will be concerned with the use of solar light in the dual-mode excitation for increasing further the process sustainability, the understanding of the role of the light-responsive support in the reaction mechanism, and the support modification for reducing the formation of $\mathrm{CO}$ as side-product, known to act as a poison for the metallic active sites. 


\section{Acknowledgement}

The University of Strasbourg IdEx Program is thanked for funding the $\mathrm{PhD}$ fellowship of Javier Ivanez. V. Papaefthimiou (ICPEES) and D. Ihiawakrim (IPCMS) are thanked for performing XPS and TEM characterizations, respectively. J. Rogowski (LUT) is thanked for performing ToF-SIMS measurements.

\section{REFERENCES}

[1] R. Schlögl, Heterogeneous catalysis, Angew. Chem. - Int. Ed. 54 (2015) 3465-3520. https://doi.org/10.1002/anie.201410738.

[2] M.J. Hülsey, C.W. Lim, N. Yan, Promoting heterogeneous catalysis beyond catalyst design, Chem. Sci. 11 (2020) 1456-1468. https://doi.org/10.1039/c9sc05947d.

[3] J.A. Herron, J. Kim, A.A. Upadhye, G.W. Huber, C.T. Maravelias, A general framework for the assessment of solar fuel technologies, Energy Environ. Sci. 8 (2015) 126-157. https://doi.org/10.1039/c4ee01958j.

[4] N.S. Lewis, G.W. Crabtree, Basic Research for Solar Energy Utilization. Report on the Basic Energy Sciences Workshop on Solar Energy Utilization, 2005. http://library1.nida.ac.th/termpaper6/sd/2554/19755.pdf.

[5] V. Nair, M.J. Muñoz-Batista, M. Fernández-García, R. Luque, J.C. Colmenares, Thermo-Photocatalysis: Environmental and Energy Applications, ChemSusChem. 12 (2019) 2098-2116. https://doi.org/10.1002/cssc.201900175.

[6] Z. Wang, H. Song, H. Liu, J. Ye, Coupling of Solar Energy and Thermal Energy for Carbon Dioxide Reduction: Status and Prospects, Angew. Chem. Int. Ed. 59 (2020) 8016-8035. https://doi.org/10.1002/anie.201907443.

[7] S. Tang, J. Sun, H. Hong, Q. Liu, Solar fuel from photo-thermal catalytic reactions with spectrum-selectivity: a review, Front. Energy. 11 (2017) 437-451. 
https://doi.org/10.1007/s11708-017-0509-z.

[8] M. Ghoussoub, M. Xia, P.N. Duchesne, D. Segal, G. Ozin, Principles of photothermal gas-phase heterogeneous CO2 catalysis, Energy Environ. Sci. 12 (2019) 1122-1142. https://doi.org/10.1039/c8ee02790k.

[9] Y. Zhao, W. Gao, S. Li, G.R. Williams, A.H. Mahadi, D. Ma, Solar- versus ThermalDriven Catalysis for Energy Conversion, Joule. 3 (2019) 920-937. https://doi.org/10.1016/j.joule.2019.03.003.

[10] S. Abate, G. Centi, P. Lanzafame, S. Perathoner, The energy-chemistry nexus: A vision of the future from sustainability perspective, J. Energy Chem. 24 (2015) 535-547. https://doi.org/10.1016/j.jechem.2015.08.005.

[11] M. Zeng, Y. Li, M. Mao, J. Bai, L. Ren, X. Zhao, Synergetic effect between photocatalysis on $\mathrm{TiO} 2$ and thermocatalysis on $\mathrm{CeO} 2$ for gas-phase oxidation of benzene on $\mathrm{TiO} 2 / \mathrm{CeO} 2$ nanocomposites, ACS Catal. 5 (2015) 3278-3286. https://doi.org/10.1021/acscatal.5b00292.

[12] R. Fiorenza, M. Bellardita, L. Palmisano, S. Scirè, A comparison between photocatalytic and catalytic oxidation of 2-Propanol over $\mathrm{Au} / \mathrm{TiO} 2-\mathrm{CeO} 2$ catalysts, $\mathrm{J}$. Mol. Catal. A Chem. 415 (2016) 56-64. https://doi.org/10.1016/j.molcata.2016.01.025.

[13] M.J. Muñoz-Batista, A.M. Eslava-Castillo, A. Kubacka, M. Fernández-García, Thermo-photo degradation of 2-propanol using a composite ceria-titania catalyst: Physico-chemical interpretation from a kinetic model, Appl. Catal. B Environ. 225 (2018) 298-306. https://doi.org/10.1016/j.apcatb.2017.11.073.

[14] Y. Zhou, D.E. Doronkin, Z. Zhao, P.N. Plessow, J. Jelic, B. Detlefs, T. Pruessmann, F. Studt, J.D. Grunwaldt, Photothermal Catalysis over Nonplasmonic Pt/TiO2 Studied by Operando HERFD-XANES, Resonant XES, and DRIFTS, ACS Catal. 8 (2018) 1139811406. https://doi.org/10.1021/acscatal.8b03724. 
[15] J. Zhang, S. Meng, X. Ye, C. Ling, S. Zhang, X. Fu, S. Chen, Synergistic effect of photocatalysis and thermocatalysis for selective oxidation of aromatic alcohols to aromatic aldehydes using Zn3In2S6@ZnO composite, Appl. Catal. B Environ. 218 (2017) 420-429. https://doi.org/10.1016/j.apcatb.2017.06.078.

[16] X. Han, L. Song, H. Xu, S. Ouyang, Light-driven low-temperature syngas production from $\mathrm{CH} 3 \mathrm{OH}$ and $\mathrm{H} 2 \mathrm{O}$ over a Pt@SrTiO3 photothermal catalyst, Catal. Sci. Technol. 8 (2018) 2515-2518. https://doi.org/10.1039/C8CY00539G.

[17] L. Wang, Y. Zhang, X. Gu, Y. Zhang, H. Su, Insight into the role of UV-irradiation in photothermal catalytic Fischer-Tropsch synthesis over TiO2 nanotube-supported cobalt nanoparticles, Catal. Sci. Technol. 8 (2018) 601-610. https://doi.org/10.1039/C7CY02304A.

[18] C. Mao, L. Yu, J. Li, J. Zhao, L. Zhang, Energy-confined solar thermal ammonia synthesis with K/Ru/TiO2-xHx, Appl. Catal. B Environ. 224 (2018) 612-620. https://doi.org/10.1016/j.apcatb.2017.11.010.

[19] C. Wang, S. Fang, S. Xie, Y. Zheng, Y.H. Hu, Thermo-photo catalytic CO2 hydrogenation over Ru/TiO2, J. Mater. Chem. A. 8 (2020) 7390-7394. https://doi.org/10.1039/C9TA13275A.

[20] B. Lu, F. Quan, Z. Sun, F. Jia, L. Zhang, Photothermal reverse-water-gas-shift over $\mathrm{Au} / \mathrm{CeO} 2$ with high yield and selectivity in $\mathrm{CO} 2$ conversion, Catal. Commun. 129 (2019) 105724. https://doi.org/10.1016/j.catcom.2019.105724.

[21] B. Xie, R.J. Wong, T.H. Tan, M. Higham, E.K. Gibson, D. Decarolis, J. Callison, K.F. Aguey-Zinsou, M. Bowker, C.R.A. Catlow, J. Scott, R. Amal, Synergistic ultraviolet and visible light photo-activation enables intensified low-temperature methanol synthesis over copper/zinc oxide/alumina, Nat. Commun. 11 (2020). https://doi.org/10.1038/s41467-020-15445-z. 
[22] H. Liu, H. Song, W. Zhou, X. Meng, J. Ye, A Promising Application of Optical Hexagonal TaN in Photocatalytic Reactions, Angew. Chem. Int. Ed. 57 (2018) 1678116784. https://doi.org/10.1002/anie.201810886.

[23] D. Zheng, G. Wei, L. Xu, Q. Guo, J. Hu, N. Sha, Z. Zhao, LaNixFe1-xO3 $(0 \leq x \leq 1)$ as photothermal catalysts for hydrocarbon fuels production from $\mathrm{CO} 2$ and $\mathrm{H} 2 \mathrm{O}, \mathrm{J}$. Photochem. Photobiol. A Chem. 377 (2019) 182-189. https://doi.org/10.1016/j.jphotochem.2019.03.045.

[24] P. Christopher, H. Xin, S. Linic, Visible-light-enhanced catalytic oxidation reactions on plasmonic silver nanostructures, Nat. Chem. 3 (2011) 467-472. https://doi.org/10.1038/nchem.1032.

[25] X. Meng, T. Wang, L. Liu, S. Ouyang, P. Li, H. Hu, T. Kako, H. Iwai, A. Tanaka, J. Ye, Photothermal conversion of $\mathrm{CO} 2$ into $\mathrm{CH} 4$ with $\mathrm{H} 2$ over Group VIII nanocatalysts: An alternative approach for solar fuel production, Angew. Chem. - Int. Ed. 53 (2014) 11478-11482. https://doi.org/10.1002/anie.201404953.

[26] X.Y.X.N. Guo, Z.F. Jiao, G.Q. Jin, X.Y.X.N. Guo, Photocatalytic fischer-tropsch synthesis on graphene-supported worm-like ruthenium nanostructures, ACS Catal. 5 (2015) 3836-3840. https://doi.org/10.1021/acscatal.5b00697.

[27] Y.Y. Cai, X.H. Li, Y.N. Zhang, X. Wei, K.X. Wang, J.S. Chen, Highly efficient dehydrogenation of formic acid over a palladium- nanoparticle-based mott-schottky photocatalyst, Angew. Chem. - Int. Ed. 52 (2013) 11822-11825. https://doi.org/10.1002/anie.201304652.

[28] M. Yadav, Q. Xu, Liquid-phase chemical hydrogen storage materials, Energy Environ. Sci. 5 (2012) 9698-9725. https://doi.org/10.1039/c2ee22937d.

[29] X. Liu, S. Li, Y. Liu, Y. Cao, Formic acid: A versatile renewable reagent for green and sustainable chemical synthesis, Cuihua Xuebao/Chinese J. Catal. 36 (2015) 1461-1475. 
https://doi.org/10.1016/S1872-2067(15)60861-0.

[30] J. Wojciechowska, M. Jędrzejczyk, J. Grams, N. Keller, A.M. Ruppert, Enhanced Production of $\gamma$-Valerolactone with an Internal Source of Hydrogen on Ca-Modified TiO 2 Supported Ru Catalysts, ChemSusChem. 12 (2019) 639-650. https://doi.org/10.1002/cssc.201801974.

[31] Y. Kuwahara, W. Kaburagi, T. Fujitani, Catalytic transfer hydrogenation of levulinate esters to $\gamma$-valerolactone over supported ruthenium hydroxide catalysts, RSC Adv. 4 (2014) 45848-45855. https://doi.org/10.1039/c4ra08074b.

[32] A.M. Ruppert, M. Jędrzejczyk, N. Potrzebowska, K. Kaźmierczak, M. Brzezińska, O. Sneka-Płatek, P. Sautet, N. Keller, C. Michel, J. Grams, Supported gold-nickel nanoalloy as a highly efficient catalyst in levulinic acid hydrogenation with formic acid as an internal hydrogen source, Catal. Sci. Technol. 8 (2018) 4318-4331. https://doi.org/10.1039/c8cy00462e.

[33] A.M. Ruppert, M. Jędrzejczyk, O. Sneka-Płatek, N. Keller, A.S. Dumon, C. Michel, P. Sautet, J. Grams, Ru catalysts for levulinic acid hydrogenation with formic acid as a hydrogen source, Green Chem. 18 (2016) 2014-2028. https://doi.org/10.1039/c5gc02200b.

[34] B. Coşkuner Filiz, E.S. Gnanakumar, A. Martínez-Arias, R. Gengler, P. Rudolf, G. Rothenberg, N.R. Shiju, Highly Selective Hydrogenation of Levulinic Acid to $\Gamma$ Valerolactone Over Ru/ZrO2 Catalysts, Catal. Letters. 147 (2017) 1744-1753. https://doi.org/10.1007/s10562-017-2049-x.

[35] J.S. Spendelow, A. Wieckowski, Electrocatalysis of oxygen reduction and small alcohol oxidation in alkaline media, Phys. Chem. Chem. Phys. 9 (2007) 2654-2675. https://doi.org/10.1039/b703315j.

[36] A. Lewera, W.P. Zhou, C. Vericat, J.H. Chung, R. Haasch, A. Wieckowski, P.S. 
Bagus, XPS and reactivity study of bimetallic nanoparticles containing Ru and Pt supported on a gold disk, Electrochim. Acta. 51 (2006) 3950-3956. https://doi.org/10.1016/j.electacta.2005.11.009.

[37] P. Mars, J.J.F. Scholten, P. Zwietering, The Catalytic Decomposition of Formic Acid, in: J. Phys. Chem., 1963: pp. 35-113. https://doi.org/10.1016/S0360-0564(08)60338-7.

[38] M. Ai, Activities for the decomposition of formic acid and the acid-base properties of metal oxide catalysts, J. Catal. 50 (1977) 291-300. https://doi.org/10.1016/00219517(77)90038-0.

[39] K.S. Kim, M.A. Barteau, Structural Dependence of the Selectivity of Formic Acid Decomposition on Faceted TiO2 (001) Surfaces, Langmuir. 6 (1990) 1485-1488. https://doi.org/10.1021/la00099a009.

[40] M.A. Henderson, Complexity in the decomposition of formic acid on the $\mathrm{TiO} 2(110)$ surface, J. Phys. Chem. B. 101 (1997) 221-229. https://doi.org/10.1021/jp961494i.

[41] S. Sarina, H.Y. Zhu, Q. Xiao, E. Jaatinen, J. Jia, Y. Huang, Z. Zheng, H. Wu, Viable photocatalysts under solar-spectrum irradiation: Nonplasmonic metal nanoparticles, Angew. Chem. - Int. Ed. 53 (2014) 2935-2940. https://doi.org/10.1002/anie.201308145.

[42] A. Pinchuk, G. Von Plessen, U. Kreibig, Influence of interband electronic transitions on the optical absorption in metallic nanoparticles, J. Phys. D. Appl. Phys. 37 (2004) 3133-3139. https://doi.org/10.1088/0022-3727/37/22/012.

[43] K. Yamada, K. Miyajima, F. Mafuné, Thermionic Emission of Electrons from Gold Nanoparticles by Nanosecond Pulse-Laser Excitation of Interband, J. Phys. Chem. C. 111 (2007) 11246-11251. https://doi.org/10.1021/jp0730747.

[44] J.A. Creighton, D.G. Eadon, Ultraviolet-visible absorption spectra of the colloidal metallic elements, J. Chem. Soc. Faraday Trans. 87 (1991) 3881-3891. 
https://doi.org/10.1039/FT9918703881.

[45] T. Pakizeh, Optical absorption of nanoparticles described by an electronic local interband transition, J. Opt. (United Kingdom). 15 (2013).

https://doi.org/10.1088/2040-8978/15/2/025001.

[46] J.H. Weaver, Optical properties of Rh, Pd, Ir, and Pt, Phys. Rev. B. 11 (1975) 14161425. https://doi.org/10.1103/PhysRevB.11.1416.

[47] R. Harpeness, Z. Peng, X. Liu, V.G. Pol, Y. Koltypin, A. Gedanken, Controlling the agglomeration of anisotropic Ru nanoparticles by the microwave-polyol process, J. Colloid Interface Sci. 287 (2005) 678-684. https://doi.org/10.1016/j.jcis.2005.02.020.

[48] S. Sarina, E.R. Waclawik, H. Zhu, Photocatalysis on supported gold and silver nanoparticles under ultraviolet and visible light irradiation, Green Chem. 15 (2013) 1814-1833. https://doi.org/10.1039/c3gc40450a.

[49] X. Guo, C. Hao, G. Jin, H.Y. Zhu, X.Y. Guo, Copper nanoparticles on graphene support: An efficient photocatalyst for coupling of nitroaromatics in visible light, Angew. Chem. - Int. Ed. 53 (2014) 1973-1977. https://doi.org/10.1002/anie.201309482.

[50] Y. Dubi, I. W. Un and Y. Sivan, Thermal effects - an alternative mechanism for plasmon-assisted photocatalysis, Chem. Sci. 11 (2020) 5017-5027.

[51] P. K. Jain, Comment on "Thermal effects - an alternative mechanism for plasmonassisted photocatalysis” by Y. Dubi, I. W. Un and Y. Sivan, Chem. Sci. 11 (2020) 5017, Chem. Sci. 11 (2020) 9022-9023.

[52] Y. Sivan, J. Baraban, I. W. Un and Y. Dubi, Comment on "Quantifying hot carrier and thermal contributions in plasmonic photocatalysis", Science, 2019, 364, eaaw9367.

[53] X. Zhang, X. Li, M. E. Reish, D. Zhang, N. Q. Su, Y. Gutiérrez, F. Moreno, W. Yang, H. O. Everitt, J. Liu, Plasmon-Enhanced Catalysis: Distinguishing Thermal and 
Nonthermal Effects, Nano Lett. 18 (2018) 1714-1723.

[54] G. Baffou, I. Bordacchini, A. Baldi and R. Quidant, Simple experimental procedures to distinguish photothermal from hot-carrier processes in plasmonics, Light Sci. Appl., DOI:10.1038/s41377-020-00345-0. 


\section{Figure 1}
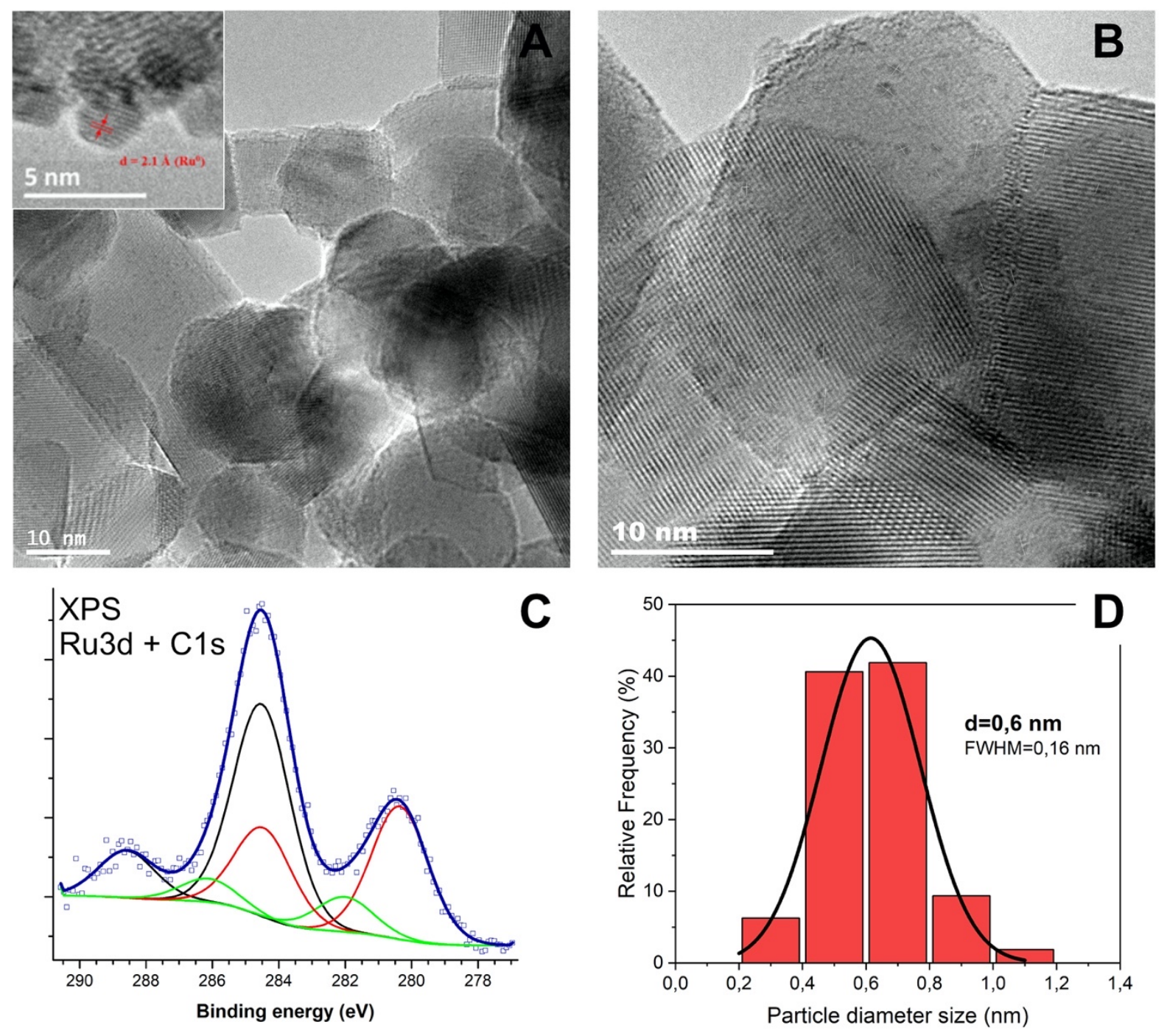

Figure 1. (A-B) TEM images of the $\mathrm{Ru} / \mathrm{TiO}_{2}$ catalyst at $0.5 \mathrm{wt} \%$ with the measured interplane distance of (101) planes of metallic $\mathrm{Ru}$; (C) the histograms of the Ru nanoparticle size distribution; (D) $\mathrm{Ru} 3 \mathrm{~d}+\mathrm{C} 1 \mathrm{~s}$ orbitals XPS profile of the $\mathrm{Ru} / \mathrm{TiO}_{2}$ catalyst at 0.5 wt. $\%$, with red: $\mathrm{Ru}^{0}$ (3d); green: oxidized $\mathrm{Ru}^{\delta+}(3 \mathrm{~d})$; black: multi-contribution envelope of adventious carbon (1s). 


\section{Figure 2}

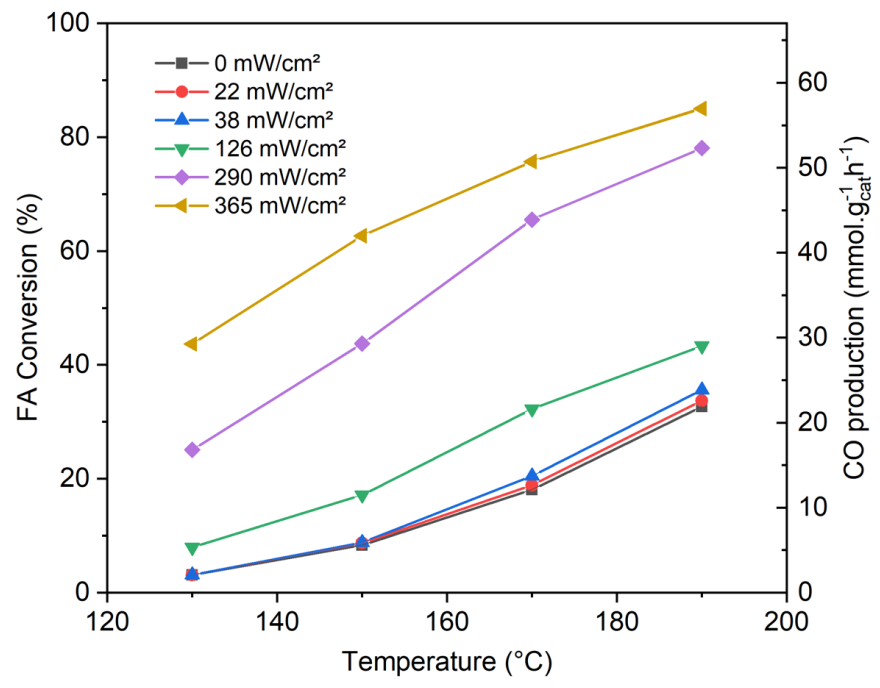

Figure 2. Influence of both the reaction temperature in the $130-190^{\circ} \mathrm{C}$ range and the UV-A irradiance $\left(0-365 \mathrm{~mW} / \mathrm{cm}^{2}\right)$ on the catalytic activity of the pure $\mathrm{TiO}_{2}-\mathrm{P} 25$ support in the gas phase FA decomposition, expressed in terms of FA conversion and $\mathrm{CO}$ formation in $\mathrm{mmol} / \mathrm{g} / \mathrm{h}$. 


\section{Figure 3}
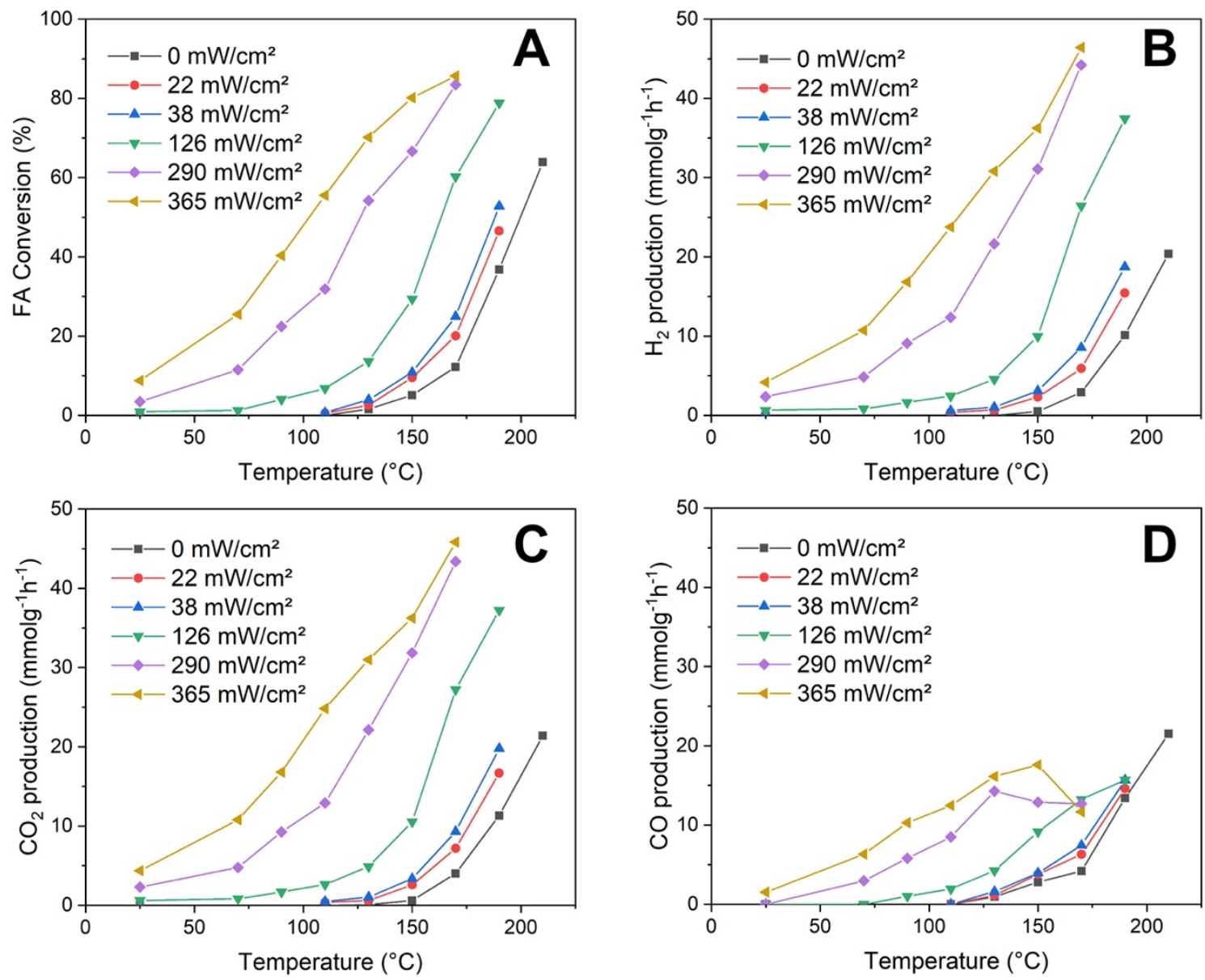

Figure 3. Influence of both the reaction temperature in the $130-190^{\circ} \mathrm{C}$ range and the UV-A irradiance $\left(0-365 \mathrm{~mW} / \mathrm{cm}^{2}\right)$ on the activity of the $\mathrm{Ru} / \mathrm{TiO}_{2}$ catalyst in the gas phase FA decomposition, expressed in terms of (A) FA conversion, (B) $\mathrm{H}_{2}$ formation in mmol/g/h, (C) $\mathrm{CO}_{2}$ formation in $\mathrm{mmol} / \mathrm{g} / \mathrm{h}$, and (D) $\mathrm{CO}$ formation in $\mathrm{mmol} / \mathrm{g} / \mathrm{h}$. The behaviour of the catalyst in specific reaction conditions such as low temperature/low irradiance or high temperature/high irradiance was not recorded, due to too low or too high FA conversion, respectively. 


\section{Figure 4}
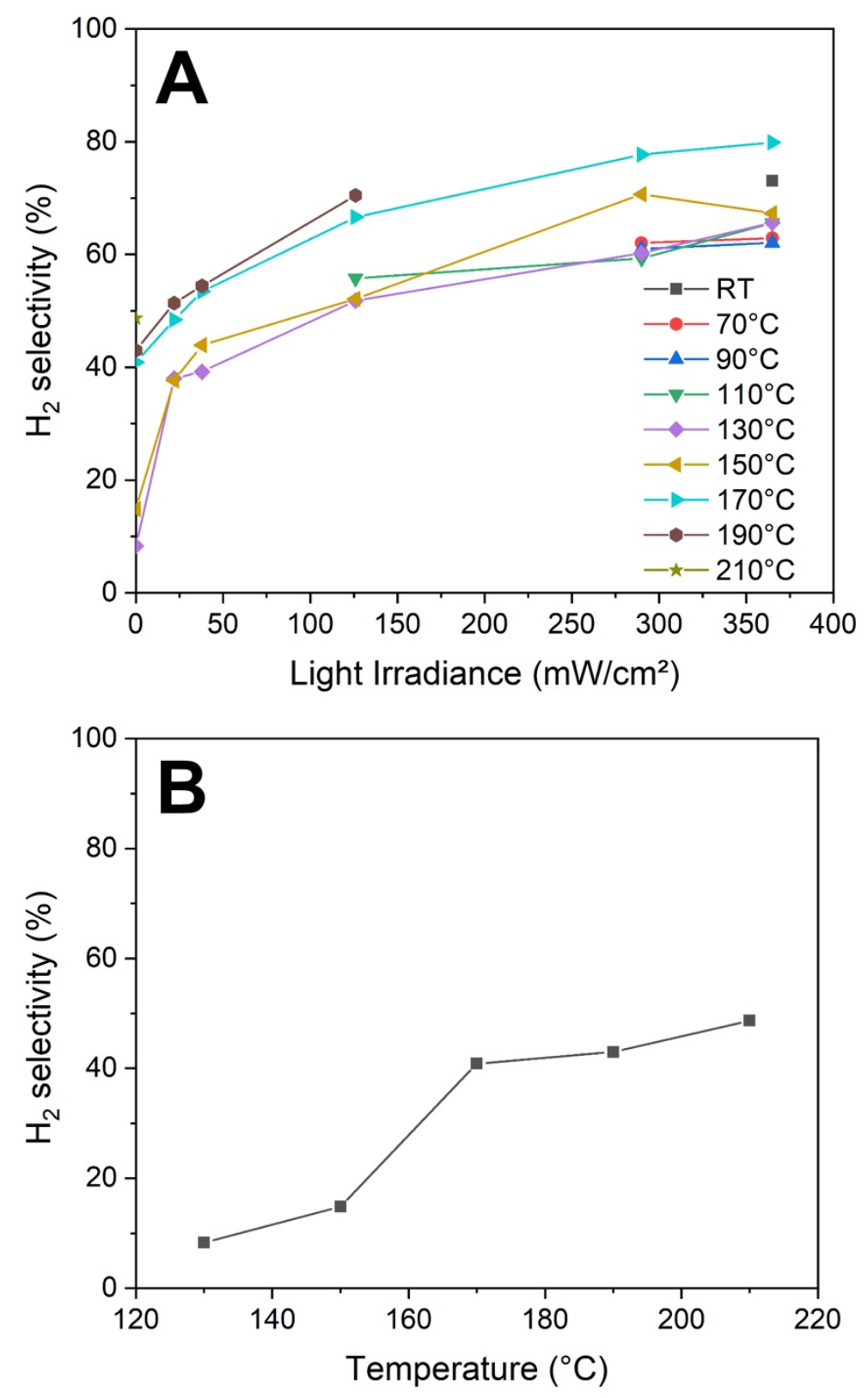

Figure 4. Influence on the selectivity to $\mathrm{H}_{2}$ of (A) the UV-A irradiance $\left(0-365 \mathrm{~mW} / \mathrm{cm}^{2}\right)$ at different reaction temperature in the $130-190^{\circ} \mathrm{C}$ range and (B) the reaction temperature in the dark. The $\mathrm{H}_{2}$ selectivity was not calculated at low temperature/low irradiance or high temperature/high irradiance, due to too low or too high FA conversion, respectively. 
Figure 5
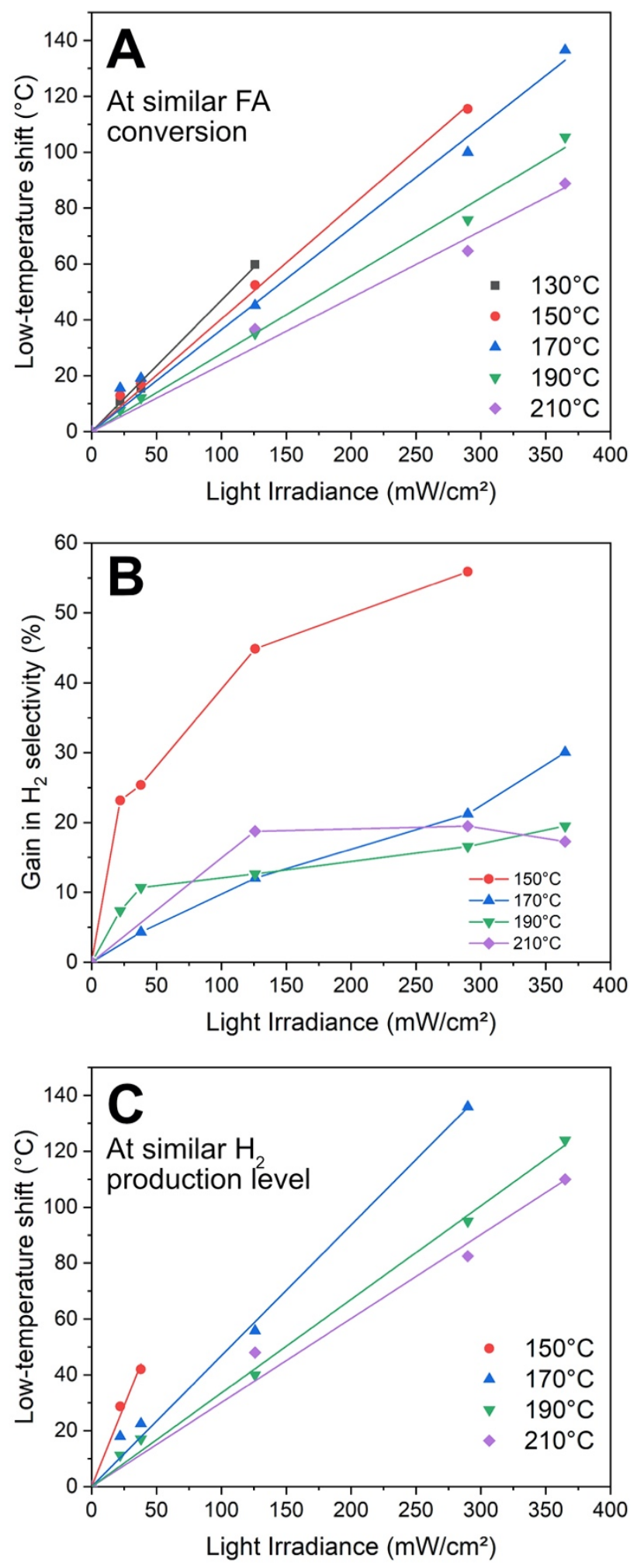
Figure 5. (A) Influence of the irradiance on the low-temperature shift gained under light while achieving a similar FA conversion as that in the dark thanks to the higher catalytic activity. The low-temperature shift is plotted by comparison to the different reaction temperatures in the dark (130-210 ${ }^{\circ}$ ); (B) Gain in $\mathrm{H}_{2}$ selectivity obtained by enabling the catalyst to operate at the lower temperature plotted in (A) thanks to the photonic excitation. The gain in $\mathrm{H}_{2}$ selectivity is plotted by comparison to the selectivity obtained at the different temperatures in the dark $\left(150-210^{\circ} \mathrm{C}\right)$; (C) Influence of the irradiance on the low-temperature shift gained under light while achieving a similar $\mathrm{H}_{2}$ production level conversion as that in the dark. The low-temperature shift is plotted by comparison to the different reaction temperatures in the dark $\left(150-210^{\circ} \mathrm{C}\right)$. The data used in those Figures are obtained by extrapolating the FA conversion as well as the $\mathrm{H}_{2}$ and $\mathrm{CO}$ productions as a function of the temperature in a linear manner between two consecutive temperature points in Fig. 3A,B,D). 


\section{Figure 6}
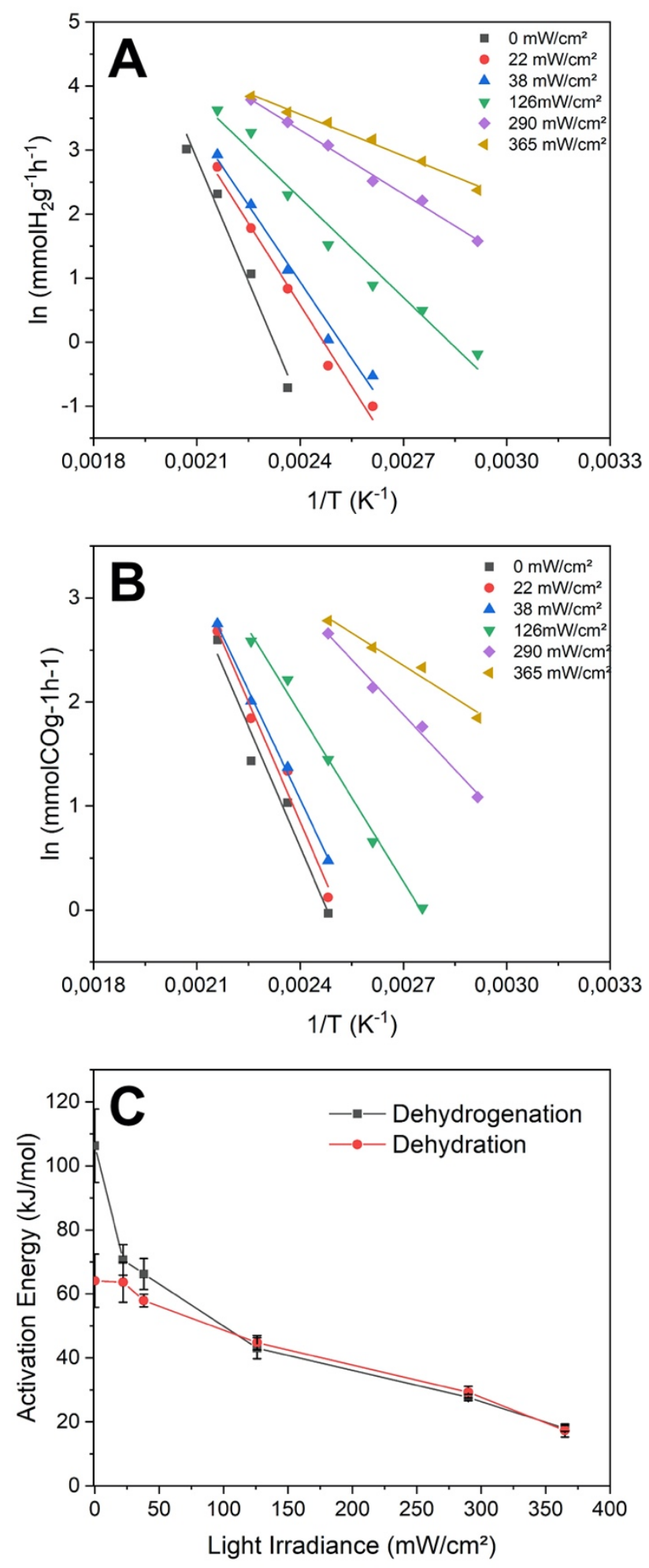

Figure 6. Arrhenius plots of the light-induced and dark reactions of (A) dehydrogenation and (B) dehydration ; (C) Influence of the UV-A light irradiance $\left(0-365 \mathrm{~mW} / \mathrm{cm}^{2}\right)$ on the apparent activation energy for both dehydrogenation and dehydration reactions. 


\title{
Supplementary material
}

\section{UV-A light-assisted gas-phase formic acid decomposition on photo-thermo $\mathrm{Ru} / \mathrm{TiO}_{2}$ catalyst}

\author{
Javier Ivanez ${ }^{1}$, Patricia Garcia-Munoz, ${ }^{1}$ Agnieszka M. Ruppert ${ }^{2}$, Nicolas Keller $^{1 *}$ \\ (1) Institut de Chimie et Procédés pour l'Energie, l'Environnement et la Santé (ICPEES), \\ CNRS/University of Strasbourg, 25 rue Becquerel 67087 Strasbourg, France. \\ (2) Institute of General and Ecological Chemistry, Faculty of Chemistry, Lodz University of \\ Technology, ul. Żeromskiego 116, 90-924, Łódź, Poland.
}

Corresponding authors(*): nkeller@unistra.fr

Figure S1. (A) UV-Vis spectrophotometry monitoring of the photo-assisted synthesis of the $\mathrm{Ru} / \mathrm{TiO}_{2}$ catalyst at $0.5 \mathrm{wt} . \%$ with the evolution of the relative concentration of the $\mathrm{Ru}$ precursor and of the corresponding UV-vis absorbance spectra upon illumination during the photo-assisted synthesis ; Photolysis is reported for comparison.

Figure S2. Influence of the UV-A irradiance $\left(0-365 \mathrm{~mW} / \mathrm{cm}^{2}\right)$ on the performances of the $\mathrm{Ru} / \mathrm{TiO}_{2}$ catalyst at different temperatures in the gas phase FA decomposition, expressed in terms of (A) FA conversion, (B) $\mathrm{H}_{2}$ formation in $\mathrm{mmol} / \mathrm{g} / \mathrm{h},(\mathbf{C}) \mathrm{CO}_{2}$ formation in $\mathrm{mmol} / \mathrm{g} / \mathrm{h}$, and (D) CO formation in $\mathrm{mmol} / \mathrm{g} / \mathrm{h}$. 


\section{Figure S1}

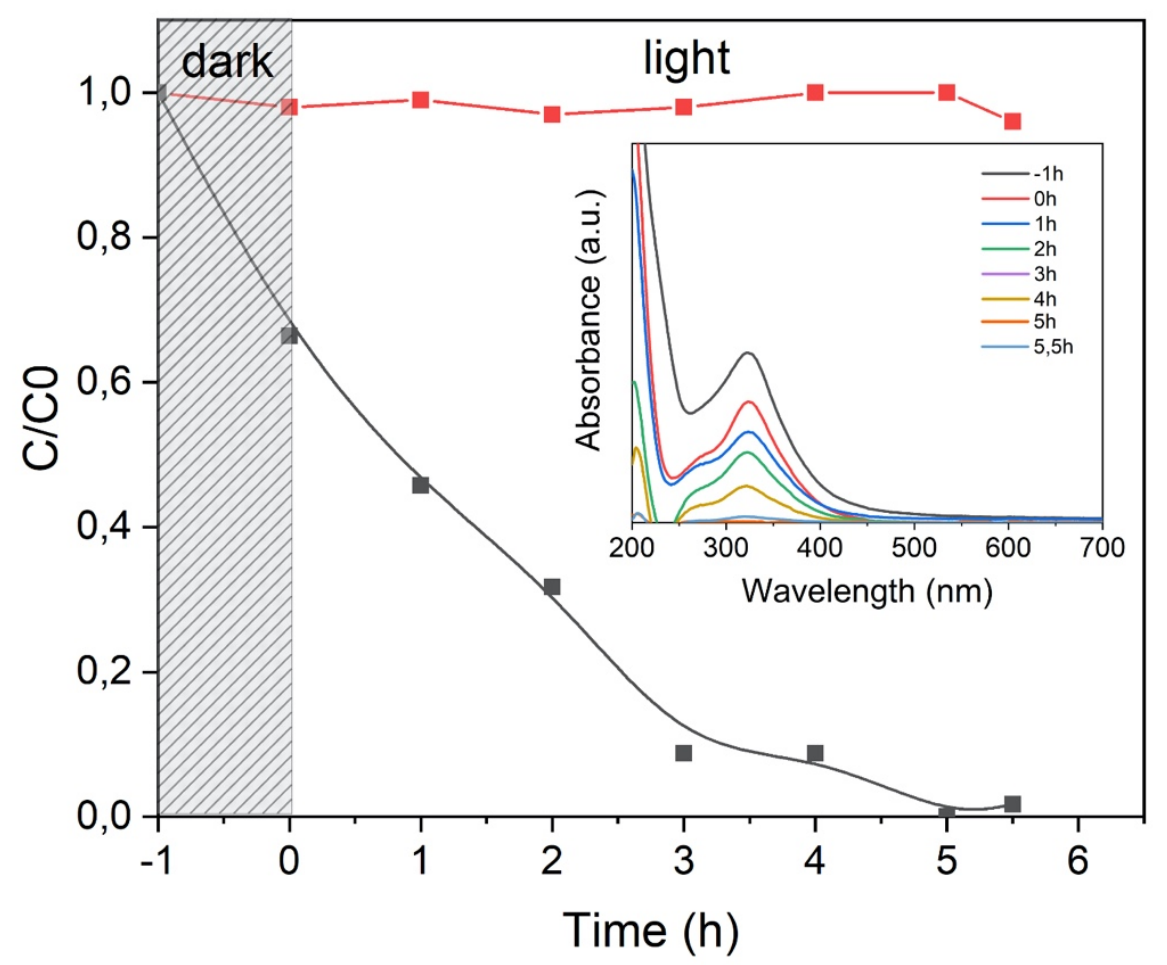

Figure S1. UV-Vis spectrophotometry monitoring of the photo-assisted synthesis of the $\mathrm{Ru} / \mathrm{TiO}_{2}$ catalyst at $0.5 \mathrm{wt} . \%$ with the evolution of the relative concentration of the $\mathrm{Ru}$ precursor and of the corresponding UV-vis absorbance spectra upon illumination during the photoassisted synthesis ; Photolysis is reported for comparison. 


\section{Figure S2}
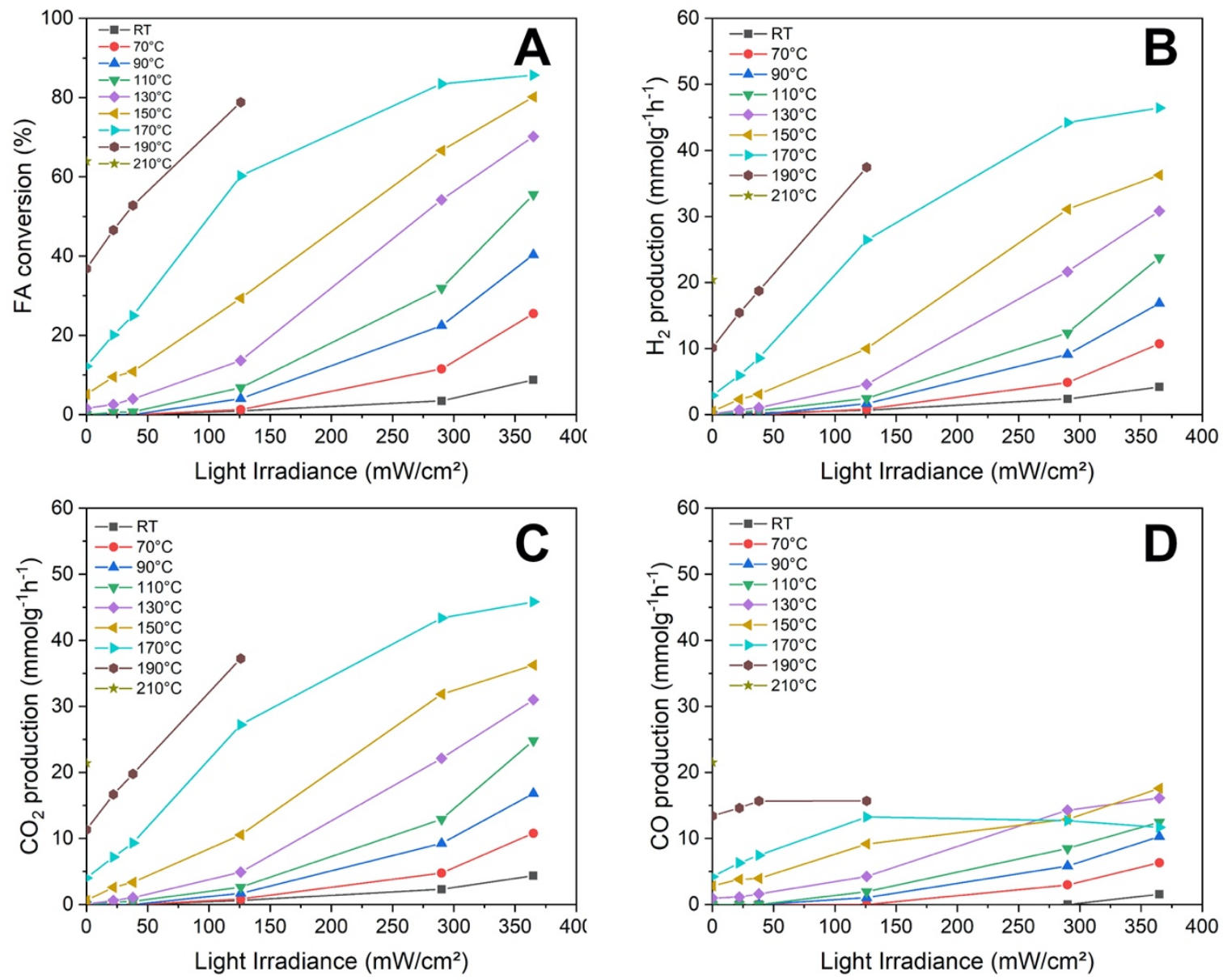

Figure S2. Influence of the UV-A irradiance $\left(0-365 \mathrm{~mW} / \mathrm{cm}^{2}\right)$ on the performances of the $\mathrm{Ru} / \mathrm{TiO}_{2}$ catalyst at different temperatures in the gas phase FA decomposition, expressed in terms of (A) FA conversion, (B) $\mathrm{H}_{2}$ formation in $\mathrm{mmol} / \mathrm{g} / \mathrm{h}$, (C) $\mathrm{CO}_{2}$ formation in $\mathrm{mmol} / \mathrm{g} / \mathrm{h}$, and (D) $\mathrm{CO}$ formation in $\mathrm{mmol} / \mathrm{g} / \mathrm{h}$. The behaviour of the catalyst in specific reaction conditions such as low temperature/low irradiance or high temperature/high irradiance were not recorded, due to too low or too high FA conversion, respectively. 